\title{
Methodology for determining the most severe risks of a construction project and identification of risky projects
}

\section{Metodología para la determinación de los riesgos más graves de un proyecto de construcción e identificación de los proyectos con más riesgo}

\author{
Fernando Vegas-Fernán dez (Main and Corresponding Author) \\ Universidad Politécnica de Madrid, Escuela Técnica Superior de Ingenieros de Caminos, Canales y Puertos (ETSICCP), \\ Departamento de Ingeniería Civil: Construcción \\ Calle Profesor Aranguren, 28043 Madrid (Spain)
}

\section{Fernando Rodríguez-López}

Universidad Politécnica de Madrid - ETSICCP, Departamento de Ingeniería Civil: Construcción

Calle Profesor Aranguren, 28043 Madrid (Spain)

fernando.rodriguezl@upm.es

Manuscript Code: 1052

Date of Acceptance/Reception: 03.12.2018/18.01.2018

DOI: 10.7764/RDLC.17.3.423

\begin{abstract}
Construction projects involve very different kinds of risks of distinct natures and demand an agile and flexible risk assessment methodology. This study has analyzed scholarly literature and best practices to find current weaknesses. Two main solutions are presented in this paper in response to the findings of the analysis: a general purpose, quantitative key risk indicator, the "Risk Visibility Factor" (Fv), that yields a single linear 0-100 value for each risk event out of its impact and likelihood; and a summarizing method based on Fv to obtain the overall risk for two or more risk events, expressed as a single equivalent risk event with its own impact and likelihood. The first solution improves current risk assessment by providing a more intuitive and understandable indicator to rate risks and projects; the second one, with recursive capability, allows risk scenarios (e.g., projects) to be seen as single risk event, without any kind of limitation on the number and nature of risks, making it easier to compare the risk severity of distinct projects. Both solutions can be used to define the risk appetite and to compare with it any risk event or scenario.
\end{abstract}

Keywords: Risk indicator, overall risk, weighting, case study, risk report.

\section{Resumen}

Los proyectos de construcción están sujetos a riesgos de diverso tipo y naturaleza, y requieren una metodología de evaluación de riesgos ágil y flexible. Este estudio analiza la literatura científica y las mejores prácticas para descubrir las debilidades de los métodos actuales. Se presentan aquí dos principales respuestas a los problemas descubiertos: un indicador de riesgo cuantitativo de propósito general, el Factor de Visibilidad del Riesgo (Fv) que asigna a cada riesgo un valor lineal de 0 a 100 partiendo de su impacto y probabilidad; y un método, basado en Fv, para resumir dos o más eventos de riesgo mediante un único evento equivalente, con su propio impacto y probabilidad. La primera solución mejora la evaluación de riesgos actual aportando un nuevo indicador más intuitivo y comprensible que expresa el nivel de riesgo de eventos y proyectos; la segunda, con capacidad recursiva, posibilita ver escenarios de riesgo como un único evento de riesgo, sin limitación en cuanto al número o naturaleza de los eventos, facilitando la comparación del nivel de riesgo de distintos proyectos. Ambas soluciones facilitan la definición del apetito de riesgo para poder comparar con él cualquier riesgo o escenario de riesgo.

Risk assessment nowadays is a common activity in most construction companies. It is used in project management, corporate risk management, and to define a company's exposure level (Huidobro, Heredia, Salmona, \& Alvarado, 2009).

Once a risk has been identified, a risk analysis is performed (International Organization for Standardization (ISO), 2018; Project Management Institute, 2017a); the easiest way to do that is just to assign a qualitative value to express the perception of the risk using a Liker's scale (Likert, 1932), e.g., low, moderate or high. A more detailed analysis can be done by assigning a separate value to both impact and likelihood (Alonso, 2005; Dziadosz \& Rejment, 2015; Project Management Institute, 2017a, 2017b; Steinberg, Everson, Martens, \& Nottingham, 2004b; West, Kenway, Hassall, \& Yuan, 2016). This method makes it possible to display a graphic representation on a likelihood/impact diagram or matrix (CEB Risk Management Leadership Council, 2013; FERMA, 2014; Okan, Stone, \& Bruine de Bruin, 2018).

As project complexity increases, the number of risk events also increases and risk models gain additional risk indicators and require that risk events be organized with matrices and weighted sections, and summarized with aggregated or 
accumulative values (Asadi \& Eswara Rao, 2018; Beasley, Branson, \& Hancock, 2010; Gul \& Ak, 2018; Steinberg, Everson, Martens, \& Nottingham, 2004a).

This article does not address the way a risk event is evaluated, but the way an evaluation is used to discover what the most severe risks are in each project and to identify the riskiest projects. One of the most popular methods for rating risks is to perform a semi-quantitative analysis by using rating scales and multiplying impact and likelihood values to obtain the level of risk or risk priority number (ISO, 2009); this product will be called "Risk Factor" ("Fr") from now on in this article. In order to identify the overall project risk, it is very common to consider the sum of probability times impact for each risk event (SPTI); in other words, the sum of the Fr for every risk event. The result is the expected value (EV) (Liu, Griffis, \& Bates, 2013; Schuyler, 2001) or the expected monetary value (EMV) when the impact is a monetary cost (Goodpasture, 2004; Project Management Institute, 2013; Raftery, 1994). There are some problems and limitations related to the use of those methods and other current methods that will be detailed in the next section.

The objective of this study is to find a solution to solve those problems with a new key risk indicator which is numerical and linear, and ranges from 0 to 100 , and with a method to obtain a "virtual" risk event which effectively summarizes two or more risk events, with recursive capability.

The new key risk indicator should yield just one number for each risk (its risk level), but it should not require a new risk assessment. Given that the evaluators would assign an impact and a likelihood for each risk, the new indicator has to be a function of those impacts and likelihoods.

The summarizing method has to admit any number of risk events of any type (Carpio de los Pinos \& González García, 2017) and has to be recursive to allow the use of previous results to summarize them at a higher level (from the breakdowns of a project risk matrix up to the whole project or group of projects). It has to yield an overall virtual risk event with its own impact and likelihood.

Description of the Problem

Risk assessors in the construction industry need to answer two main questions: "what is the risk level for each identified risk?" and "what is the overall project risk?". For the first one, current methods are somewhat limited by using risk indicators which are difficult to understand: they are not linear, they depend on the range the method defines (e.g., 1 to 16,1 to 25 , etc.), and they require a scale or a score table to reveal their severity (Project Management Institute, 2017a). For the second question, current methods do not provide a summary for project risk as one overall risk event with its impact and likelihood but a single number with the same previously said limitations.

The Fr value (and other current indicators) depends on the numerical scales used for impact and likelihood (e.g., on a typical scale where both factors are given values from 1 to 5, Fr would range from 1 to 25 and a 1 to 4 scale would yield a 1 to 16 outcome); that means that the outcome figures alone are meaningless, and they need to be referenced to the maximum possible value to be understood (e.g., $8 / 25$ or $9 / 16$ ). That issue can be easily fixed by using normalized scales of 0 to 100 for impact and $0 \%$ to $100 \%$ for likelihood, although evaluators generally use score tables from 1 to 4 or 1 to 5.

The Fr outcome is not linear. With a normalized scale, an output of 50 out of 100 is not moderate because it could be the result of an impact of 70 with a likelihood of $70 \%$ (50 is moderate to assign an impact, but not as an Fr result. That lack of linearity cannot be helped and that behavior reduces its understandability; it would be desirable to use another indicator yielding linear outcomes because the human brain manages linear information better (Babatola, 2004; Ghazali, Ayub, \& Othman, 2013; Siegler \& Opfer, 2003).

Current methods do not provide an answer to know what the overall impact and likelihood are for a given set of risk events, and they just yield a number. As an example, take two risk events with respective impacts and likelihoods 80 , $20 \%$ and $20,80 \%$. Both $\mathrm{Fr}$ are 16 but the resulting Fr, with their average impact (50) and likelihood (50\%), is 25 . As a final example, two risk events with 10,10\% and 90,90\% show that their Fr are 1 and 81 respectively, with an average of 41 , but the Fr of their average impact and likelihood, 50 and $50 \%$ respectively, would be 25 .

That paradox has led current methodologies to turn down the idea of calculating the overall impact and likelihood and to try to obtain just an overall risk value. To do that, they frequently use the sum of the SPTI method to calculate a rate or an average (Project Management Institute, 2013) (see section Introduction). 
Several issues arise when using that method: first, when it is just a sum, the resulting rate needs to be compared with a reference scale which has to be defined, tuned, and modified every time the number of risk events changes, unless the only impact considered is the risk cost. Second, it is not sensitive to any particularly high risk (a new critical risk, e.g., Ebola, could not significantly affect the result). Third, that method is based on the Central Limit Theorem (Raftery, 1994) and construction projects do not fulfill the requirements for that theorem to be applicable (a large number of independent risk events with no individual significant contribution); an analysis has been carried out with the Monte Carlo simulation which proves that the SPTI is not reliable because it is just a probabilistic average which does not consider the statistical distribution of the risk events and, frequently, it underestimates the result.

A case with a project risk assessment in a multinational technology company demonstrates the intricacies. Table 1 shows the risk analysis performed using PMBOK $^{\oplus}$ methodology (Project Management Institute, 2017a), with 5 risk events with impacts ranging from 0 to 10 and likelihoods from 0 to $100 \%$.

\begin{tabular}{lccc} 
Table 1. Risk assessment case \#1. Source: self-elaboration. \\
\hline Risk & Impact & $\begin{array}{c}\text { Likelihood } \\
\text { (\%) }\end{array}$ & $\mathrm{Fr}$ \\
\hline Risk \#1 & 8 & 40 & 3.2 \\
Risk \#2 & 9 & 80 & 7.2 \\
Risk \#3 & 8 & 30 & 2.4 \\
Risk \#4 & 7 & 40 & 2.8 \\
Risk \#5 & 7 & 50 & 3.5 \\
\hline
\end{tabular}

The defined score table was: low 1 to 3 , moderate 4 to 6 , and high 7 to 10 .

They used $\mathrm{Fr}$ to express the risk intensity, to rank the risks, and to obtain the overall project risk using SPTI, which was 3.8. The project was rated as having a "moderate risk" level.

Most risk events seem to have a low rate, about 3.0, which makes the project appear as low-risk with just one high-risk event (\#2). However, a closer study reveals that the impacts range between 7 and 8 with likelihoods between $30 \%$ and $50 \%$. The use of $\mathrm{Fr}$ here leads to a misunderstanding of the individual and overall risk levels, even with the help of a score table. The use of SPTI to obtain the project risk leads to a misunderstanding of the overall risk (3.8 is equivalent to an impact of 6.2 with a likelihood of $62 \%$ ). It will be shown later on that the actual risk level of the project is high. That project actually failed.

A new method is required to obtain a more reliable overall risk value, which is also able to provide a representative risk event with its own impact and likelihood and which has a recursive capability to allow various risk scenarios to be combined.

State of the Art

According to Huidobro et al., 2009, current popular methodologies were studied (ISO, 2009, 2018, Project Management Institute, 2017a, 2017b; Steinberg et al., 2004b) and a literature review was performed, studying more than 1,500 papers and finding 250 relevant articles, books and theses.

Many scholars highlight the need for risk indicators with overall indicators to facilitate decision making (Hamid \& Kehinde, 2017; Murakami, Tsubokura, Ono, \& Maeda, 2018; Tóth \& Sebestyén, 2014) which proves that there is not yet one clear solution.

Current works focuses on the best way to evaluate both impact and likelihood, using fuzzy methods (Elbarkouky, Fayek, Siraj, \& Sadeghi, 2016; Orojloo, Hashemy Shahdany, \& Roozbahani, 2018; Samantra, Datta, \& Mahapatra, 2017; Wu et al., 2017) and probabilistic methods usually linked to contingency calculation (Rosenberg \& Schuermann, 2006; Salah \& Moselhi, 2015; World Economic Forum, 2018).

Some recent articles propose integrated risk ratings, but they are only intended for limited scenarios (Fuertes Peña \& Romero Rubio, 2003; Grishunin \& Suloeva, 2016; Ivanets, 2017; Nicol \& Chadès, 2017; Shen, Wang, Li, \& Wang, 2018). Others are based on the artificial neural network (ANN), although this is not really a new concept, and could be excessively complicated (Akinsola, 1997; Lam \& Siwingwa, 2017; Lhee, 2014). 
Sometimes these proposed methods use the sum of probability times impact (SPTI) which makes them unreliable, as was said before.

There are many interesting proposals for improving risk assessment in projects, although many times the proposed methods are too complex for construction companies, which are frequently not up-to-date with the latest methodologies and do not possess the skills necessary to apply them (Daston, 1988; Zou, Chen, \& Chan, 2010). Literature, as said before, is focused on the best way to evaluate both impact and likelihood, which is very important, but does not address the previously described problems.

Some papers are aligned with the approach used in this article to find a solution (Abdelghany \& Ezeldin, 2010; Al-Bahar \& Crandall, 1990; Karakhan \& Gambatese, 2017; Royer, 2000), although it will be shown that this paper goes further.

\section{Risk Factor analysis}

The most extensively used indicator is the Risk Factor Fr. It is a function of the impact $I$ and the likelihood $P: F r=I \times P$.

Fr is a sort of quantitative indicator (ANSI/ASIS/RIMS, 2015; Carpio de los Pinos \& González García, 2017; Project Management Institute, 2017a) because it yields single numbers. Its use is commonplace because it is simple, but it has some limitations and it introduces unwanted problems, as was described in the section "Description of the Problem".

It is not very intuitive and could give a wrong idea of the risk level, e.g., insinuating that 40 out of 100 is moderate or low. As a result, it is necessary to use tables or charts to fully understand the meaning of an Fr value and its relation to the defined risk appetite.

Furthermore, the Fr curves on an impact/likelihood heat map lie very close to each other in the top right corner but far apart in the bottom left corner, as a consequence of its undesirable lack of linearity. That fact makes it not very sensitive when both impact and likelihood are under 50 and 50\% (Figure 1).

A slightly better alternative is to use the square root $\mathrm{Fr}_{\text {mod }}=\mathrm{VFr}$. It solves some of those issues but introduces new problems. It yields a better and more uniform coverage of the risk map, with equally spaced risk level lines along the diagonal line (the line on the impact-likelihood graph that joins the point with impact 0 and likelihood $0 \%$, and the point with impact 100 and likelihood 100\%); each curve corner is located at the point where impact equals likelihood, and this value defines the curve level value. Those properties give $\mathrm{Fr}_{\text {mod }}$ a more linear behavior, as can be seen in the vertical sections across the diagonal line (Figure 1).

However, $\mathrm{Fr}_{\text {mod }}$ level curves are not equally spaced along the lateral map limits, where Impact $=100$ and where Likelihood $=100 \%$, (unlike Fr curves) and although that could be a good behavior when Impact $=100$, it is not desirable when Likelihood $=100 \%$, yielding, for instance, an Frmod of 40 with an impact of only 16. 

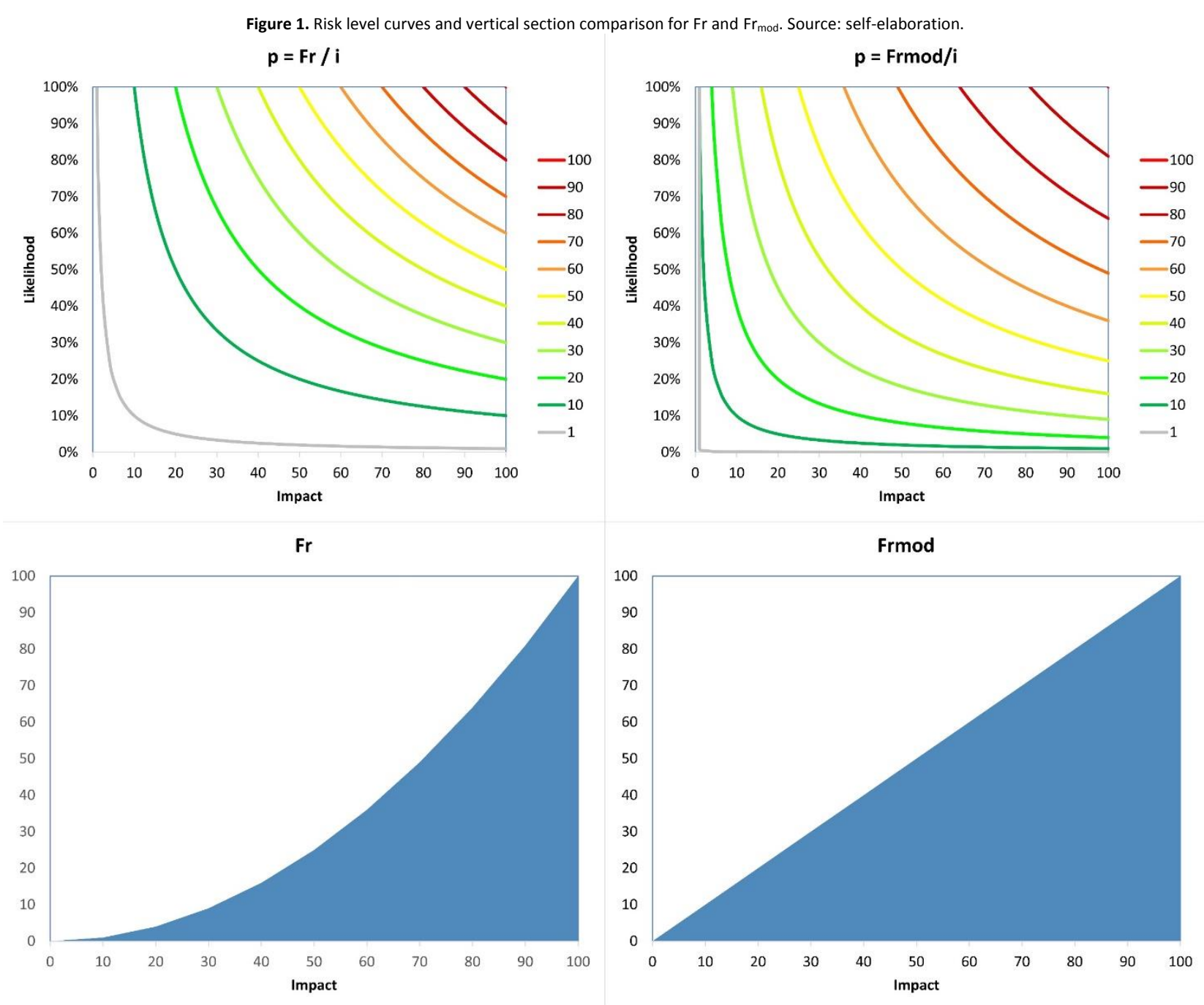

Methodology

Once the issues had been identified, the best possible solutions needed to be outlined. Interviews, meetings and brainstorming with practitioners and scholars were conducted to define the requirements which would be the reference to try to find out any nearly existing solution.

Three main requirements were defined through these sessions: to take advantage of the current qualitative risk analysis using impact and likelihood to obtain quantitative risk values; to obtain numerical results for each risk event, risk matrix, and the whole project; and to use linear scales to evaluate risks events and to analyze results.

A mathematical analysis of the Risk Factor Fr was performed to understand the reason why it did not fit requirements (see the previous section) and a mathematical solution to those issues was investigated.

Once the study had yielded a preliminary solution, it was checked with practitioners to confirm that it was easy to use and understandable; the results were then compared with those of real projects, and, finally, tested against simulation models.

Research and practical experience have been combined to carry out this work (Aven, 2018).

Results and discussion

This article introduces a new quantitative risk indicator and a method to summarize several risk events into one equivalent risk event as a solution to the need to improve risk assessment in the construction industry and to solve the previously described problems. 
The Visibility Factor is a complement to existing indicators: impact, likelihood and any other specific indicator. It is not intended to substitute current indicators, but it is more intuitive and improves understandability. The summarizing capability based on Fv allows the project to be analyzed from a more objective point of view.

\section{New Indicator Definition: The Visibility Factor}

Conceptually, the new indicator should yield equally spaced risk level curves when drawing level curves on an impactlikelihood diagram (Al-Bahar \& Crandall, 1990; Karakhan \& Gambatese, 2017). The chosen shape for these curves is $y=$ $F / x, F$ being a constant to be defined. To draw those lines with a horizontal distance $a$, the equation and its solution are:

$$
\begin{gathered}
P=\frac{F}{i-\frac{a}{k_{1}}+C}+\frac{\frac{a}{k_{2}}-C}{100} \\
a=\frac{100 P+C+(i+C) \frac{k_{1}}{k_{2}} \sqrt{\left(100 P+C+(i+C) \frac{k_{1}}{k_{2}}\right)^{2}-4\left(100 P i-100 F+100 P C+C i+C^{2}\right) \frac{k_{1}}{k_{2}}}}{2} \times k_{2}
\end{gathered}
$$

The constant $F$ defines the curvature of the lines to avoid the lines cutting the axis where $\operatorname{Impact}=0$ and Likelihood $=0$, $C$ introduces an offset, and $K_{1}$ and $K_{2}$ allow the curves to be bent and break their symmetry. Their values were determined after a series of interviews with practitioners, where they were asked about their preferred curve shape. A symmetrical curve model was chosen although a second option was also considered. Two indicators were defined: the risk Visibility Factor (Fv) and the modified Visibility Factor ( $F v_{\text {mod }}$ ). Their constant values are shown in Table 2.

\begin{tabular}{ccc} 
Table 2. Parameter definition for $F v$ and $F v_{\text {mod. }}$ Source: self-elaboration. \\
\hline Parameters & \multicolumn{1}{c}{$F v$} & $F_{\text {mod }}$ \\
\hline $\mathrm{F}$ & 1.00 & 1.93 \\
$\mathrm{C}$ & 10.00 & 13.88 \\
$\mathrm{~K}_{1}$ & 1.00 & 0.92 \\
$\mathrm{~K}_{2}$ & 1.00 & 1.37 \\
\hline
\end{tabular}

The simplified resulting equation for Fv is:

$$
F v=\frac{100 p+20+i-\sqrt{10000 p^{2}+i^{2}-200 p i+400}}{2}
$$

Two other equations are useful for obtaining the impact and likelihood values for a given Fv using the other value (impact or likelihood) and will be used in the next section:

$$
i=\frac{20 F v-F v^{2}+100 P F v-1000 p}{100 P+10-F v} \quad p=\frac{1}{i-F v+10}+\frac{F v-10}{100}
$$

The resulting curves are shown in Figure 2. Both indicators yield linear behavior along the diagonal (see the vertical sections) and their level curves provide the desired uniform coverage. Fv curves are entirely symmetrical, which made them the first choice of the interviewees. Fvmod provides a higher sensitivity with low-probability risk events, improving the response of $\mathrm{Fr}_{\text {mod }}$ (see section "Risk Factor analysis"), although its response is not perfect when the impact is high. Fv has been tested using random simulation models and with construction projects (see next sections). In other types of projects, with very low likelihoods, it would be better to use Fvmod or even other studied modified versions not included in this article. 

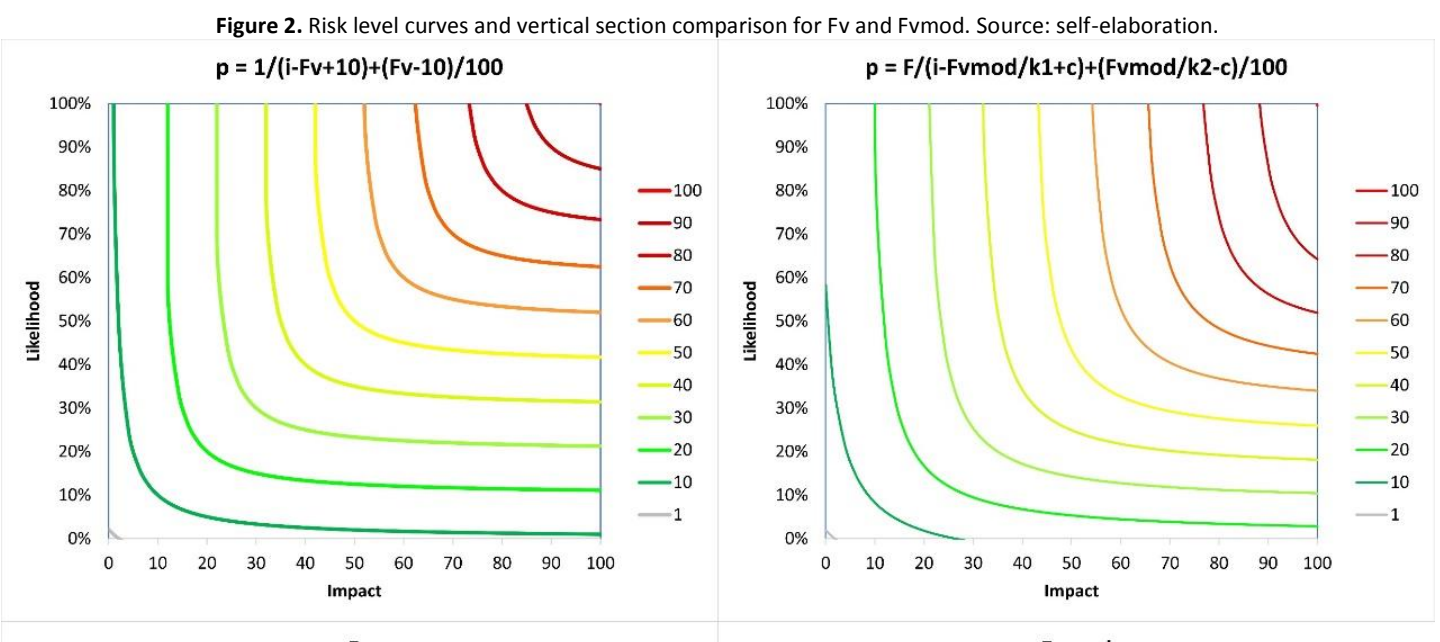

Fv
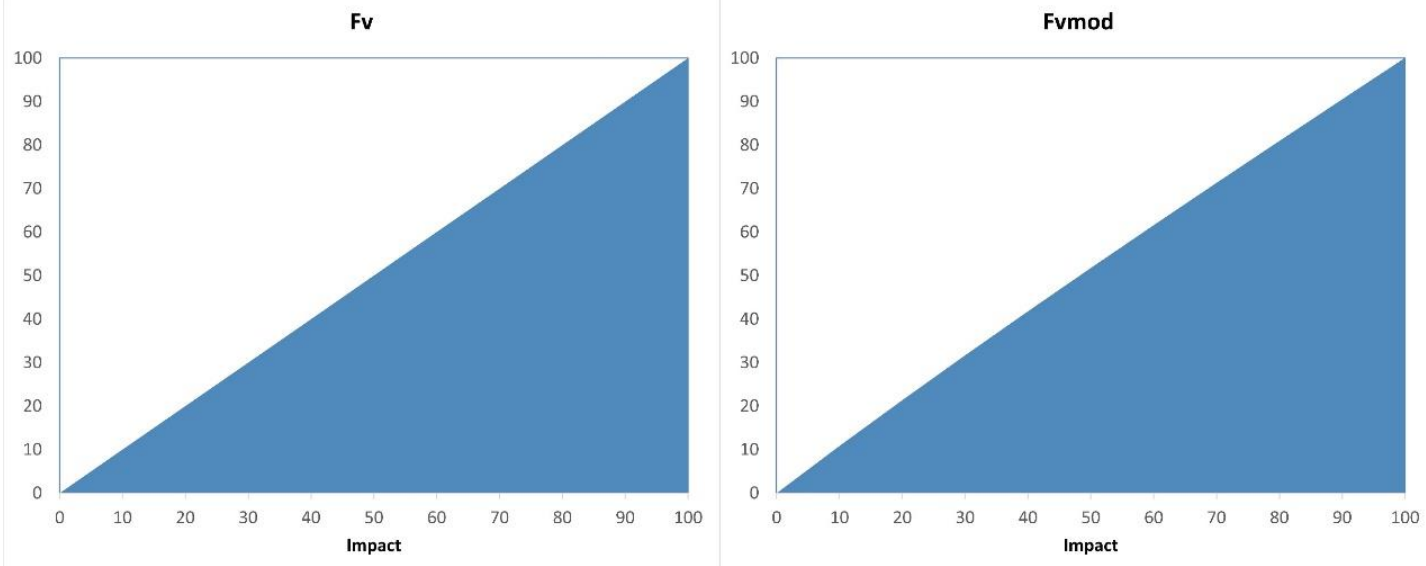

\section{Limitations}

The application framework of this indicator is potentially unlimited because it only needs an impact and a likelihood. Its value does not include additional dimensions such as vulnerability and speed of onset (Curtis \& Carey, 2012), although they are not commonplace in the construction industry and Fv can evaluate any risk consequence as a separated risk.

\section{New Method to Summarize two or more Risk Events}

The overall risk result must meet two requirements: to be representative of the risk scenario and to have its own impact and likelihood. A new method based on the Visibility Factor has been developed which, while simple (Cretu, Stewart, \& Berends, 2011), nevertheless offers the desired solution. It uses a quadratic average as proposed by Abdelghany \& Ezeldin, 2010 and Royer, 2000 and takes advantage of the Fv risk value. This way, the resulting weight for an original weight $W_{j}$ becomes for each risk event:

$$
W^{\prime}{ }_{j}=\left(F v_{j} \times W_{j}\right)^{2}
$$

The quadratic approach is the mathematical response to the paradigm of a health report: a cardiovascular situation with imminent danger of myocardial infarction (heart attack) and a dental situation with no cavities or other pathologies. Clearly, the overall health risk is not the average but a high risk. Construction projects behave like this following the Pareto law, with many low-risk events and with a few of them having a high risk. A single average, even using weights, will usually yield an underestimated value.

By using $W_{j}^{\prime}$, the weighted average is calculated for the impact, likelihood and $F v$ values, resulting in $I_{m}, P_{m}$, and $F v_{m}$. With $F v_{m}$ and the equations (3), it is possible to obtain the corresponding $I_{a}$ and $P_{a}$ values for $P_{m}$ and $I_{m}$, respectively. Graphically, this means they are on the curve of the impact/likelihood map that displays $F v_{m}$.

Once those new auxiliary points have been defined, $\left(I_{a}, P_{m}\right)$ and $\left(I_{m}, P_{a}\right)$, both of them on the Fv $=\mathrm{Fv}$ curve, the mean values for their impacts and likelihoods, $I_{m a}$ and $P_{m a}$, are obtained. The resulting average point $\left(I_{m a}, P_{m a}\right)$ will have a Visibility Factor $F v_{a}$, slightly different from the reference $F v_{m}$ and will be off the $F v=F v_{m}$ curve. The difference $F v_{a}-F v_{m}$ is 
minuscule and the values $I_{m a}$ and $P_{m a}$ are multiplied by the ratio $\mathrm{Fv} / \mathrm{Fv}_{\mathrm{a}}$ before recalculating the $\mathrm{Fv}$ value for them which, now, will match the proposed Fvm.

\section{Example}

A construction project (case \#2) is used to show the result of the proposed method. It has 20 defined risks which are graphed in Figure 3.

Figure 3. Overall risk calculation for case \#2. Source: self-elaboration.

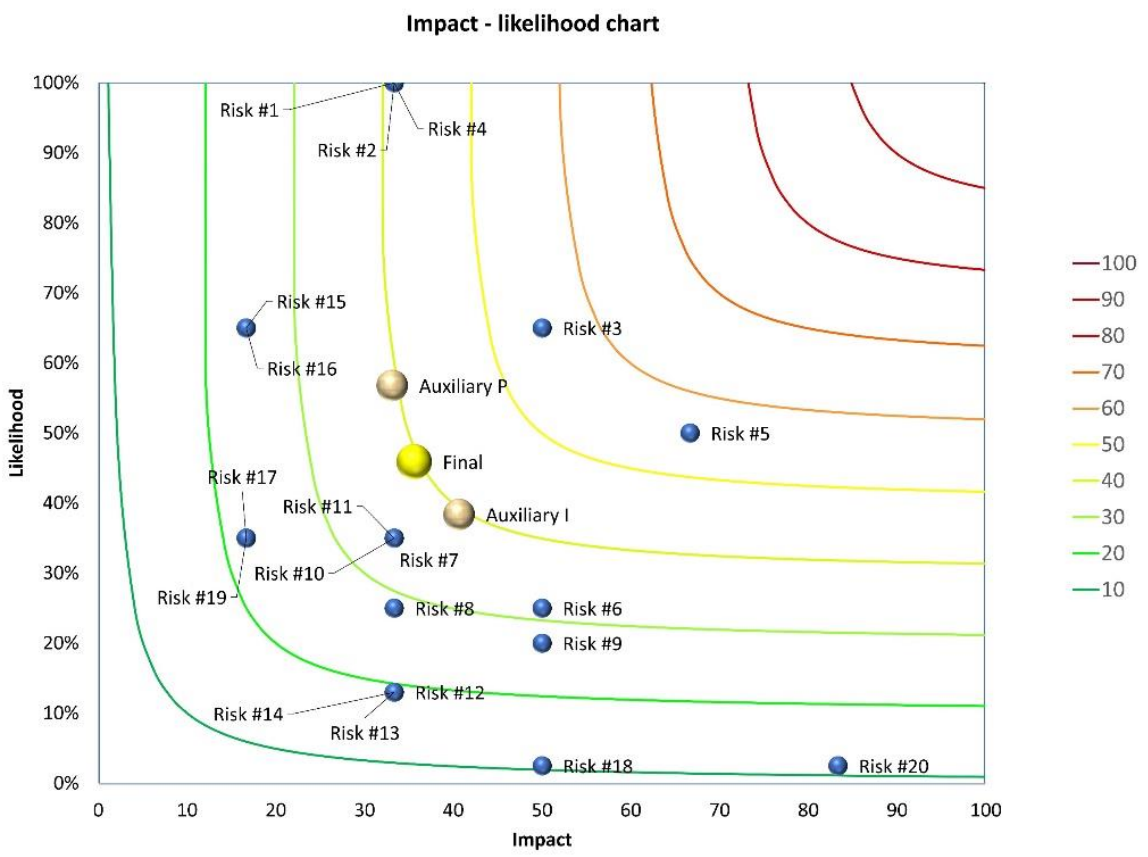

The overall risk has an impact of 36 with a likelihood of $46 \%$ and Fv of 39.

The final results in each of the approaches for case \#2 are:

\begin{tabular}{lccc}
\multicolumn{4}{c}{ Table 3. Comparative analysis for averages. Source: self-elaboration. } \\
\hline \multicolumn{1}{c}{ Approach } & I & P & Fv \\
\hline 1 Simple mean & 29 & $31 \%$ & 30 \\
2 Visibility Factor & 36 & $46 \%$ & 39 \\
\hline
\end{tabular}

Test

With a view to proving the quality of the proposed solution, a series of simulations have been conducted with random data for impact, likelihood, and weight, checking the suitability of the solution.

It has also been compared to other methods in real projects and it yields a higher risk value for overall project risk than those that use average-based methods, as would be expected. With closed, fine-tuned models (intended for specific types of risk or a defined number of risks, with rating scales fine-tuned based on experience) the results are similar, although the proposed method is always more sensitive and flexible (Carpio de los Pinos \& González García, 2017; Fuertes Peña \& Romero Rubio, 2003).

The previously seen case \#1 has been analyzed with these tools (Table 4).

\begin{tabular}{ccccc}
\multicolumn{5}{c}{ Table 4. Risk assessment case \#1 with Fv. Source: self-elaboration. } \\
\hline Risk & Impact & $\begin{array}{c}\text { Likelihood } \\
\text { (\%) }\end{array}$ & Fr & Fv \\
\hline Risk \#1 & 8 & 40 & 3.2 & 48 \\
Risk \#2 & 9 & 80 & 7.2 & 84 \\
Risk \#3 & 8 & 30 & 2.4 & 38 \\
Risk \#4 & 7 & 40 & 2.8 & 47 \\
Risk \#5 & 7 & 50 & 3.5 & 56 \\
\hline
\end{tabular}


The new method yields for the overall risk an impact of 79 , a likelihood of $58 \%$ and $\mathrm{Fv}=64$, which is more in concordance with the case severity (the original score was 3.8 out of 10 ).

Another case, case \#3, is a construction project with more than 80 assessed risk events, with 25 identified risks rating both impact and likelihood from 0 to 5 . After normalizing to 0 to 100 scales, the SPTI method yielded an average of 45 before mitigation and 25 after mitigation, while the method proposed here yields Fv $=68$ and 49 respectively. The fact of defining the overall risk components (impact and likelihood) helps risk evaluators choose whether to mitigate the impact, likelihood or both (Figure 4).

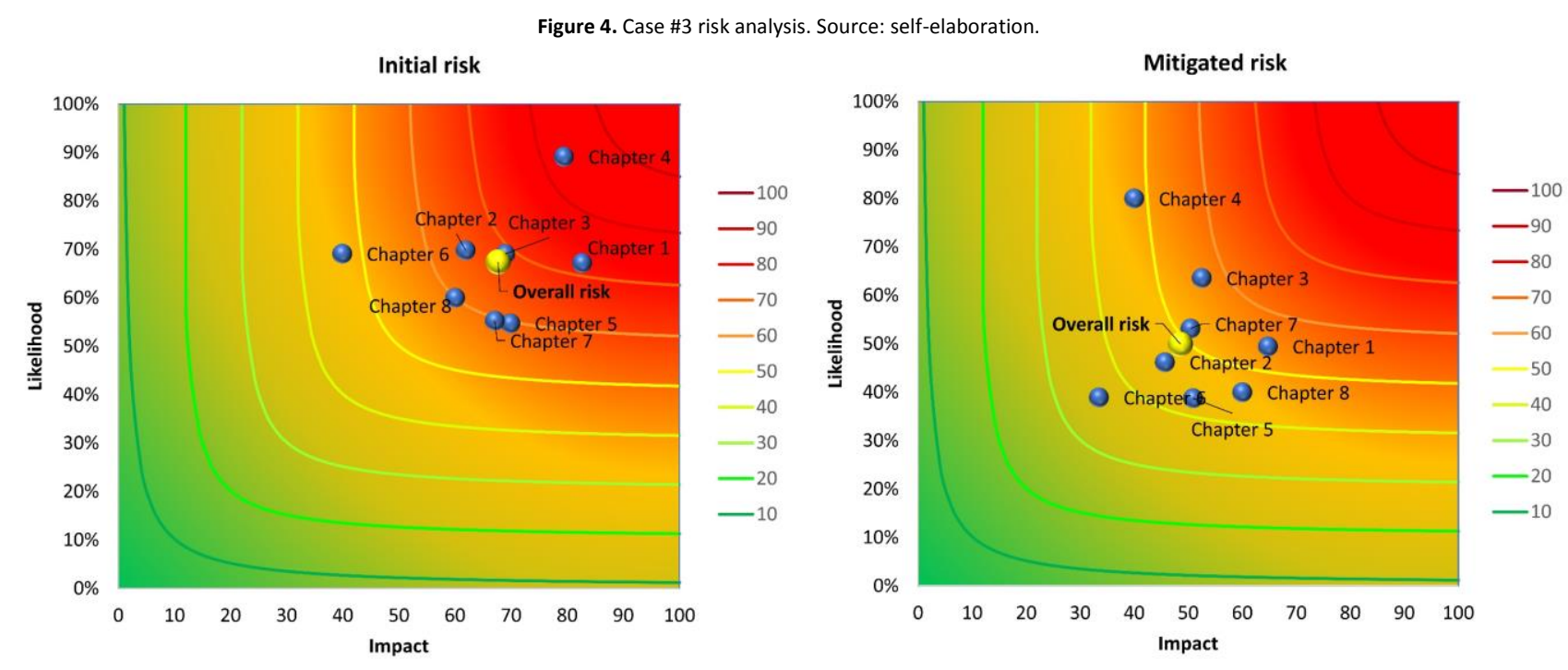

\section{Risk Appetite and Risk Aversion}

The decision about taking a risk involves risk perception and risk attitude. Risk attitude, also called risk appetite, depends on the character of the organizations and people involved (Hillson \& Murray-Webster, 2004; Ingram \& Thompson, 2012) and it should be related to an expected utility. The Arrow-Pratt coefficients of absolute risk aversion focus on utility (Kranton, 2005; Pratt, 1964; Rubbini, 2005; Torres, 2015) while the Visibility Factor focuses on damage.

The Visibility Factor will be helpful when implementing a risk appetite framework in the companies because it gives a quantitative way to express the risk appetite. Its linearity allows risk managers to understand risk severity and decide whether an Fv of 50, for instance, is acceptable or not.

According to Arrow-Pratt, the higher the absolute risk aversion $r_{A}$ value, the riskier the decision is. An adaptation of the Arrow-Pratt theory was performed to compare Fv and Fr; unlike Arrow-Pratt's curves, risk curves will not be concave, but convex, because they do not display utility but risk. It has been mathematically proven that the absolute risk aversion is always higher for Fr; this confirms the intuitive and visual perception that Fv always yields a higher value than Fr for a given impact-likelihood event risk.

This new method is currently being used in a multinational construction company based in Spain to rate risk events and projects and to establish the risk appetite (Vegas-Fernández, 2017) and it helps managers obtain the overall risk level for any group of projects (Vegas-Fernández \& Rodríguez López, 2017).

The recurrent feature of the new method also allows risks to be grouped and summarized in broader scopes, to show, for instance, which nature, type and dimension of risk is the most relevant in each continent.

Figure 5 shows the result of the study of thousands of construction projects, showing that contractual risks in Asia are the most severe risks, with an Fv value of 89 (data have been slightly altered for confidentiality reasons). 


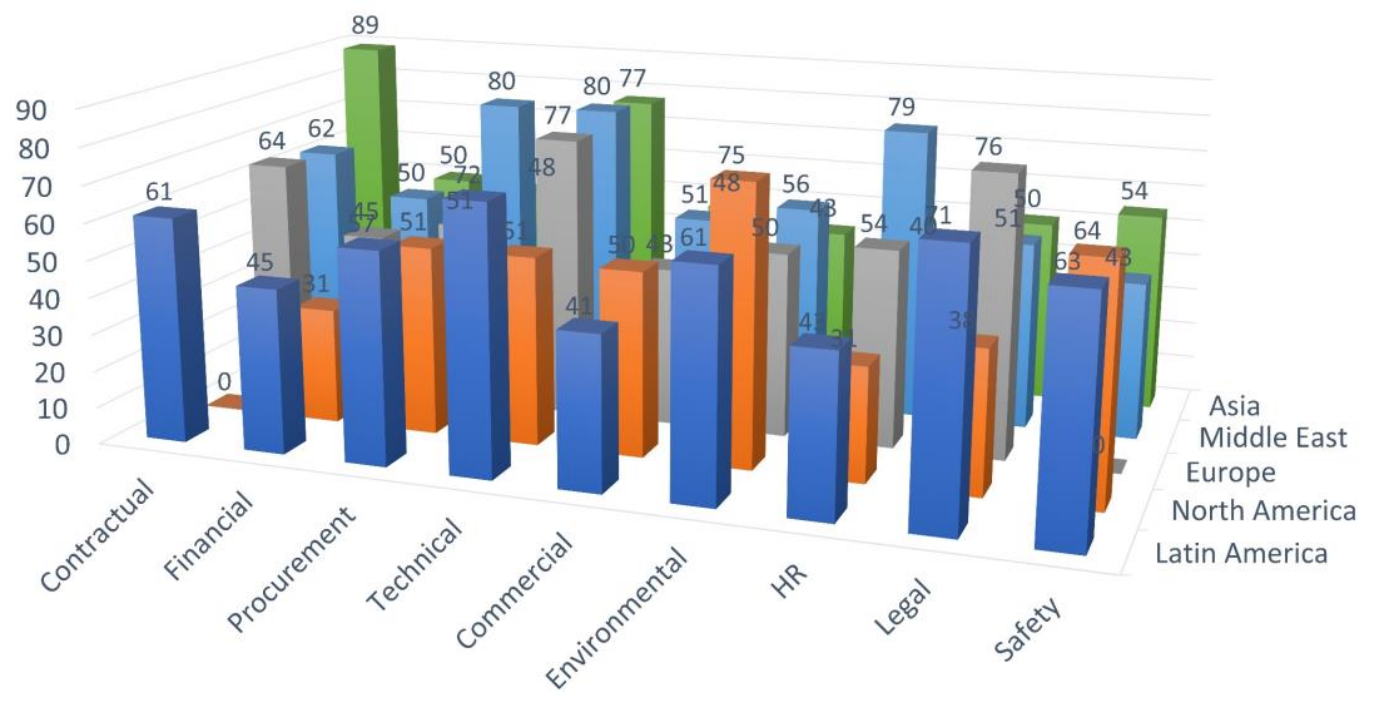

- Latin America $\quad$ North America Europe $\quad$ Middle East $\quad$ Asia

This article presents a new generic key risk indicator, the Visibility Factor Fv, and a methodology based on it to summarize a scenario of risk events, yielding an overall risk point with its own impact, likelihood and Visibility Factor.

The conceptual pillar is the Visibility Factor Fv, the simplicity of which will allow business units and enterprises to adopt it as a general primary indicator to compare, classify and prioritize the risk in their projects and activities.

The summarizing method offers a more reliable and safer way to calculate overall project risk than the traditional average-based methods and allows country-level or continent-level risk values to be obtained.

Mitigation analysis, tracking of risk evolution over time in a project lifecycle, and the comparison of any risk situation with the established risk appetite will be very easy using Fv. Risk reports will be smarter and shorter, with business intelligence capabilities. With these findings, companies will improve the way they communicate and understand the risk of a project, country or enterprise.

The method presented is not intended for project risk cost calculation, which should be obtained using a probabilistic method.

The authors sincerely thank the Escuela Técnica Superior de Ingenieros de Caminos, Canales y Puertos (Universidad Politécnica de Madrid, Spain), for its help and support; and Mrs. Katherine Reddington for her continuous encouragement and her unlimited help.

Abdelghany, Y., \& Ezeldin, A. S. (2010). Classification of Risks for International Construction Joint Ventures (ICJV) Projects. In Construction Research Congress 2010: Innovation for Reshaping Construction Practice (pp. 1254-1263). Banff, Alberta, Canada: ASCE. https://doi.org/10.1061/41109(373)126

Akinsola, A. O. (1997). an Intelligent Model of Variations' Contingency on Construction Projects. University of Wolverhampton. University of Wolverhampton, Wolverhampton, UK.

Al-Bahar, J. F., \& Crandall, K. C. (1990). Systematic Risk Management Approach for Construction Projects. Journal of Construction Engineering and Management, 116(3), 533-546. https://doi.org/10.1061/(asce)0733-9364(1990)116:3(533)

Alonso, F. G. (2005). Gerencia de riesgos. Anales de Mecánica y Electricidad, 82, 32-34. 
Asadi, S. S., \& Eswara Rao, V. (2018). An integrated approach to a critical analysis of risk management in construction projects. International Journal

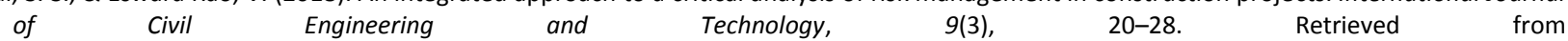
http://www.iaeme.com/MasterAdmin/Journal_uploads/IJCIET/VOLUME_9_ISSUE_3/IJCIET_09_03_004.pdf

Aven, T. (2018). Reflections on the Use of Conceptual Research in Risk Analysis. Risk Analysis, 38(11), 2415-2423. https://doi.org/10.1111/risa.13139

Babatola, M. (2004). Developing a KRI Program: Guidance for the Operational Risk Manager. Retrieved June 6, 2016, from http://fsroundtable.org/wpcontent/uploads/2015/07/KRIprogram0904.pdf

Beasley, M. S., Branson, B. C., \& Hancock, B. V. (2010). Developing key risk indicators to strengthen enterprise risk management. How key risk indicator can sharpen focus on emerging risks. In C. The Committee of Sponsoring Organizations of the Treadway Commission (Ed.) (December, pp. 120). Durham, NC 27707, USA: The Committee of Sponsoring Organizations of the Treadway Commission, COSO,. Retrieved from papers2://publication/uuid/A17DB7CA-6EC5-4F23-84FE-DB4996794C37

Carpio de los Pinos, A. J., \& González García, M. de las N. (2017). Critical analysis of risk assessment methods applied to construction works. Revista de La Construcción, 16(1), 104-114. https://doi.org/10.7764/RDLC.16.1.104

CEB Risk Management Leadership Council. (2013). A Guide to Risk Rating Criteria. In Annual Executive Retreat. London, UK: CEB Risk Management Leadership Council. Retrieved from https://www.cebglobal.com/content/risk-management/us/en/member/assetviewer.html?referrerTitle=A Guide to Risk Rating Criteria\&filePath=/content/dam/riskmanagement/us/en/General/PDF/13/12/PRO_BRF_Risk_Ratings_final.pdf\&contentType=researchreport\&searchStr

Cretu, O., Stewart, R., \& Berends, T. (2011). Risk Management for Design and Construction. Hoboken, New Jersey, USA: Wiley.

Curtis, P., \& Carey, M. (2012). Risk Assessment in Practice. Durham, NC 27707, USA: The Committee of Sponsoring Organizations of the Treadway Commission, COSO.

Daston, L. J. (1988). La domesticación del riesgo. Probabilidad matemática y seguros (1650-1830). Llull, 11(20), 19-50. Retrieved from https://dialnet.unirioja.es/servlet/articulo?codigo=62047

Dziadosz, A., \& Rejment, M. (2015). Risk Analysis in Construction Project-Chosen Methods. Procedia Engineering, 122, $258-265$.

Elbarkouky, M. M. G., Fayek, A. R., Siraj, N. B., \& Sadeghi, N. (2016). Fuzzy arithmetic risk analysis approach to determine construction project contingency. Journal of Construction Engineering and Management, 142(12), 4016070. https://doi.org/10.1061/(ASCE)CO.1943-7862.0001191

FERMA. (2014). European Risk and Insurance Report. Executive Summary of the FERMA Risk Management. Benchmarking survey 2014. 7th edition. Retrieved April 27, 2016, from http://www.ferma.eu/about/publications/benchmarking-surveys/benchmarking-survey-2014/

Fuertes Peña, J., \& Romero Rubio, J. C. (2003). Análisis comparativo de los principales métodos de evaluación del riesgo de incendio. Seguridad y Salud En El Trabajo, $\quad 25, \quad 12-17 . \quad$ from http://comisionnacional.insht.es/InshtWeb/Contenidos/Documentacion/TextosOnline/Rev_INSHT/2003/25/seccionTecTextCompl2.pdf

Ghazali, M., Ayub, A., \& Othman, A. R. (2013). Preschool Children's Representation of Numbers on a Linear Number Line: Implications to Teaching and Learning of Number Concepts. IOSR Journal Of Humanities And Social Science, 14(6), 87-92. https://doi.org/10.9790/0837-1468792

Goodpasture, J. (2004). Quantitative Methods in Project Management. Quantitative Methods in Project Management. Plantation, FL 33324, USA: J. Ross Publishing.

Grishunin, S., \& Suloeva, S. (2016). Development of project risk rating for telecommunication company. In Internet of Things, Smart Spaces, and Next Generation Networks and Systems (pp. 752-765). St. Petersburg, Russia: Springer. Retrieved from https://link.springer.com/chapter/10.1007/978-3-319-46301-8_66

Gul, M., \& Ak, M. F. (2018). A comparative outline for quantifying risk ratings in occupational health and safety risk assessment. Journal of Cleaner Production, 196, 653-664. https://doi.org/10.1016/j.jclepro.2018.06.106

Hamid, R. A., \& Kehinde, F. J. (2017). Choosing an Appropriate Contingency Sum Estimating. Planning Malasia Journal, 15(1), 13-20. https://doi.org/10.21837/pmjournal.v15.i6.217

Hillson, D., \& Murray-Webster, R. (2004). Understanding and Managing Risk Attitude. Farnham, GU9 7PT,UK: Gpmfirst.

Huidobro, J., Heredia, B., Salmona, M., \& Alvarado, L. (2009). Inclusión en la gestión de riesgos en el estudio de ofertas para licitaciones de proyectos de construcción. Revista de La Construcción, 8(2), 27-37. Retrieved from http://www.redalyc.org/html/1276/127619798003/

Ingram, D., \& Thompson, M. (2012). What's Your Risk Attitude? Harvard Business Review. Harvard Business Review, (Dec 22, 2016). Retrieved from https://hbr.org/2012/06/whats-your-risk-attitude-and-h

International Organization for Standardization (ISO). (2009). Risk management - Risk assessment techniques. International Organization for Standardization, ISO 31010:(31010:2009).

International Organization for Standardization (ISO). (2018). Risk Management - Guidelines. International Organization for Standardization, ISO 31000:(31000:2018).

Ivanets, O. (2017). Systemic Risk Index-Integrated Indicator of Financial Sustainability. European Journal of Sustainable Development, 6(4), 502-510. https://doi.org/10.14207/ejsd.2017.v6n4p502

Karakhan, A. A., \& Gambatese, J. A. (2017). Identification, Quantification, and Classification of Potential Safety Risk for Sustainable Construction in the United States. Journal of Construction Engineering and Management, 143(7), 04017018. https://doi.org/10.1061/(ASCE)CO.1943-7862.0001302

Kranton, R. (2005). Measuring Risk Aversion. Retrieved December 2016, http://public.econ.duke.edu/ rek8/econ604/lecturenotes/topic2notesparttwo.pdf 
Lam, T. Y. M., \& Siwingwa, N. (2017). Risk management and contingency sum of construction projects. Journal of Financial Management of Property and Construction, 22(3), 237-251. https://doi.org/10.1108/JFMPC-10-2016-0047

Lhee, S. C. (2014). Finding Significant Factors to Affect Cost Contingency on Construction Projects Using ANOVA Statistical Method. Architectural Research, 16(2), 75-80. https://doi.org/10.5659/aikar.2014.16.2.75

Likert, R. (1932). A technique for the measurement of attitudes. Archives of Psychology, 22(140), 21-55. Retrieved from https://legacy.voteview.com/pdf/Likert_1932.pdf

Liu, M., Griffis, F. H., \& Bates, A. J. (2013). Compensation structure and contingency allocation in integrated project delivery. In ASEE Annual Conference and Exposition, Conference Proceedings (Vol. 23, p. 1). Retrieved from http://www.scopus.com/inward/record.url?eid=2-s2.0$84884316423 \&$ partnerlD=40\&md5=e5e8988cc7c9c48023cfe338d79a8124

Murakami, M., Tsubokura, M., Ono, K., \& Maeda, M. (2018). New "loss of happy life expectancy" indicator and its use in risk comparison after Fukushima disaster. Science of the Total Environment, 615, 1527-1534. https://doi.org/10.1016/j.scitotenv.2017.09.132

Nicol, S., \& Chadès, I. (2017). A preliminary approach to quantifying the overall environmental risks posed by development projects during environmental impact assessment. Plos One, 12(7), e0180982. https://doi.org/10.1371/journal.pone.0180982

Okan, Y., Stone, E. R., \& Bruine de Bruin, W. (2018). Designing graphs that promote both risk understanding and behavior change. Risk Analysis, 38(5), 929-946. https://doi.org/10.1111/risa.12895

Orojloo, M., Hashemy Shahdany, S. M., \& Roozbahani, A. (2018). Developing an integrated risk management framework for agricultural water conveyance and distribution systems within fuzzy decision making approaches. Science of the Total Environment, 627, $1363-1376$. https://doi.org/10.1016/j.scitotenv.2018.01.324

Pratt, J. W. (1964). Risk aversion in the small and in the large. Econometrica, 32(1/2), 122-136. https://doi.org/00129682(196401/04)32:1/2<122:RAITSA $>2.0 . C O ; 2-W$

Project Management Institute. (2013). Project Risk Management. In A Guide to the Project Management Body of Knowledge (PMBOK ${ }^{\circledR}$ Guide). (5th ed., pp. 309-354). Newtown Square, PA, USA: Project Management Institute, Inc.

Project Management Institute. (2017a). A Guide to the Project Management Body of Knowledge PMBOK ${ }^{\circledR}$ Guide. In Project Management Institute (Ed.), A Guide to the Project Management Body of Knowledge PMBOK ${ }^{\circledR}$ Guide. (6th ed., pp. 358-412). Newtown Square, Pensilvania 19073-3299, USA: Project Management Institute, Inc

Project Management Institute. (2017b). Construction Extension to the PMBOK ${ }^{\circledR}$ Guide. (6th ed.). Newtown Square, PA: Project Management Institute, Inc.

Raftery, J. (1994). Risk analysis in project management. London EC4P 4EE, UK: Spon Press.

Rosenberg, J. V, \& Schuermann, T. (2006). A general approach to integrated risk management with skewed, fat-tailed risks. Journal of Financial Economics, 79(3), 569-614. https://doi.org/10.1016/j.jfineco.2005.03.001

Royer, P. S. (2000). Risk Management: The Undiscovered Dimension of Project Management. Project Management Journal, 31(1), 6-13. https://doi.org/10.1177/875697280003100103

Rubbini, C. (2005). Decisiones Bajo Incertidumbre. Microeconomía II. Retrieved December 2, 2016, from http://www.depeco.econo.unlp.edu.ar/wp/wp-content/uploads/2017/05/docen10.pdf

Salah, A., \& Moselhi, O. (2015). Contingency modelling for construction projects using fuzzy-set theory. Engineering, Construction and Architectural Management, 22(2), 214-241. https://doi.org/10.1108/ECAM-03-2014-0039

Samantra, C., Datta, S., \& Mahapatra, S. S. (2017). Fuzzy based risk assessment module for metropolitan construction project: An empirical study. Engineering Applications of Artificial Intelligence, 65(2007), 449-464. https://doi.org/10.1016/j.engappai.2017.04.019

Schuyler, J. (2001). Risk and decision analysis in projects. Princeton, New Jersey, USA: Project Management Institute, Inc.

Shen, Q., Wang, J., Li, Y., \& Wang, L. (2018). Railway Risk Assessment of the EPC General Contract in Ethiopia Based on the Improved Fuzzy Comprehensive Evaluation Method. In ASCE (Ed.), ICCREM 2016 (pp. 1376-1387). Edmonton, Canada: ASCE. https://doi.org/doi:10.1061/9780784480274.169

Siegler, R. S., \& Opfer, J. E. (2003). The Development of Numerical Estimation: Evidence for Multiple Representations of Numerical Quantity. Psychological Science, 14(3), 237-250. https://doi.org/10.1111/1467-9280.02438

Steinberg, R. M., Everson, M. E. A., Martens, F. J., \& Nottingham, L. E. (2004a). Enterprise Risk Management - Integrated Framework. Application Techniques. (C. The Committee of Sponsoring Organizations of the Treadway Commission, Ed.). Committee of Sponsoring Organizations of the Treadway Commission.

Steinberg, R. M., Everson, M. E. A., Martens, F. J., \& Nottingham, L. E. (2004b). Enterprise Risk Management - Integrated Framework. Jersey City, NJ: Committee of Sponsoring Organizations of the Treadway Commission.

Torres, R. (2015). Coeficientes de aversión al riesgo. Retrieved November 21, 2016, from http://ciep.itam.mx/ rtorres/ecofin/coeficientes.pdf

Tóth, T., \& Sebestyén, Z. (2014). Integrated risk management process for building projects. Procedia Engineering, 85(2014), 510-519. https://doi.org/10.1016/j.proeng.2014.10.578

Vegas-Fernández, F. (2017). Sistema de información de riesgos: Factor de Visibilidad. El Profesional de La Informacion, $26(6)$, 1065-1075. https://doi.org/10.3145/epi.2017.nov.06 
Vegas-Fernández, F., \& Rodríguez López, F. (2017). Factor de Visibilidad: un indicador cuantitativo para valorar el riesgo del proyecto. Observatorio Gerencia de Riesgos, 6(Julio-diciembre), 18-21. Retrieved from https://agers.es/wp-content/uploads/2017/12/revista-dic17.pdf

West, C., Kenway, S., Hassall, M., \& Yuan, Z. (2016). Why do residential recycled water schemes fail? A comprehensive review of risk factors and impact on objectives. Water Research, 102, 271-281. https://doi.org/10.1016/j.watres.2016.06.044

World Economic Forum. (2018). The global risks report 2018, 13th edition. (World Economic Forum, Ed.) (13th ed.). Geneva, Switzerland: World Economic Forum. Retrieved from http://www3.weforum.org/docs/WEF_GRR18_Report.pdf

Wu, Y., Li, L., Xu, R., Chen, K., Hu, Y., \& Lin, X. (2017). Risk assessment in straw-based power generation public-private partnership projects in China: A fuzzy synthetic evaluation analysis. Journal of Cleaner Production, 161(0), 977-990. https://doi.org/10.1016/j.jclepro.2017.06.008

Zou, P. X. W., Chen, Y., \& Chan, T.-Y. (2010). Understanding and Improving Your Risk Management Capability: Assessment Model for Construction Organizations. Journal of Construction Engineering and Management, 136(8), 854-863. https://doi.org/10.1061/(asce)co.1943-7862.0000175 